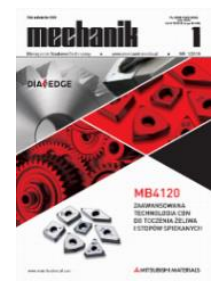

How to cite this article:

Authors: Marek Wyleżoł, Piotr Frączek

Title of article: „, Virtual model of a protective helmet for people waiting for cranioplastic treatment”

Mechanik, No. 1 (2019)

DOI: https://doi.org/10.17814/mechanik.2019.1.8

\title{
Virtual model of a protective helmet for people waiting for cranioplastic treatment
}

\author{
MAREK WYLEŻOŁ \\ PIOTR FRACZCEK*
}

Dr hab. inż. Marek Wyleżoł, prof. PŚ, marek.wylezol@polsl.pl, https://orcid.org/0000-0001-6324-510X - Politechnika Śląska, Polska mgr inż. Piotr Frączek, piotr.fraczek35@gmail.com - Politechnika Śląska, Polska

Article refers to discuss the virtual helmet model designed for people waiting for cranioplasty treatment. The helmet should protect the trauma zone until surgery. It should also be easy in everyday use. The model was made using ergonomic and strength analysis. All work was supported by the CATIA v5 system.

KEYWORDS: cranioplasty, virtual modelling

\section{Introduction}

Cranioplasty is a neurosurgical procedure performed on patients with congenital cranial bone defects, defects resulting from trauma or intentional surgery (e.g. removal of neoplastic lesions). In most cases, cranial bone injuries are also associated with brain damage, which can lead to disability, and in the worst circumstances - be the direct cause of patient death $[4,5]$.

Depending on the size of the injury in the skull structure, it can be associated with disfigurement, which is a significant aesthetic problem, as well as limiting the possibility of proper functioning. In most cases, the skull bone defect can be successfully completed to restore the natural shape of the skull [4].

Considering the size of the damage in the skull, it was assumed that in the case of a defect with a diameter exceeding $50 \mathrm{~mm}$, it is necessary to undergo cranioplasty surgery. Minor skull bone defects are generally not reconstructed unless for cosmetic reasons [1].

The goal of cranioplasty is to correct the deformations of the patient's head, as well as to supplement the bone defect, which - for cosmetic reasons and due to the need to provide the required brain protection against further potential damage and mechanical injuries - is the biggest problem in neurosurgery.

One of the most important requirements for the re-construction of the skull bone is to provide adequate protection at the bone defect - not only before surgery, but also during rehabilitation. The human brain is a delicate structure, so any undesirable action of external forces can cause an increase in the primary trauma zone and, as a consequence - deterioration of the patient's neurological condition and even his death.

The modern market offers a number of protective solutions for each age group of patients after craniocerebral trauma. In the case of cranioplasty surgery and skull deformation treatment, most rehabilitation products are made to individual orders, which results from the need to adjust the protector to the shape and type of injury. The procedure related to the selection of individual head protection can be very expensive because it usually involves the need to take measurements during multi-stage consultations. Unfortunately, universal helmets and protectors available on the market do not provide as accurate protection as personalized products. Meanwhile, the use of such an additional, universal cover in the zone of bone absence of the skull seems necessary due to the long waiting time for cranioplasty and the high costs of such surgery.

The authors came up with a proposal for a universal, adaptive protective helmet. Its most important advantages are:

- lower purchase cost compared to a personalized protector,

- availability

- ensuring protection of a large area of the skull and elimination of specialist visits for the selection and adjustment of the helmet. 


\section{Helmet design}

The following design and construction assumptions were made:

- helmet is intended for adults;

- helmet must provide the most accurate protection for the trauma area located anywhere in the parietal or frontal part of the skull bone;

- shielding elements should eliminate contact of the protected zone with other objects;

- helmet should consist of a minimum number of elements and have a low weight;

- helmet design must allow easy adjustment of the guard (or guards) by the user;

- helmet should be equipped with one or two covers (visors) - depending on the size of the protected zone;

- helmet construction must ensure stable positioning of the guards in the desired position;

- helmet selection and individual fit should not require a specialist's visit.

The main problem that had to be solved during the development of the helmet construction was the decision on how to protect the place of injury and regulate this protection depending on the size of the bone defect. Finally, the concept was chosen which should meet the assumptions with the highest technical probability.

It was decided that the construction of the helmet will consist of:

- framework, which will be in direct contact with the user's head;

- movable protective element (shield, visor), whose main task will be to absorb any pressure or impact, partially absorb its energy, and then transfer the remaining energy to the truss.

Framework 2 (fig. 1) will be the outer part of the helmet, giving it a basic form. Movement of the shield 1 (fig. 1) will be carried out by using the shape of the hole 3, having the shape of a "bean", so that the user will be able to determine one of three positions of the cover. The fastening belt 5 (fig. 1) together with the elastic elements 4 will allow you to adjust the helmet size to fit it perfectly to your head and ensure comfort during everyday use. Chinstrap 6 (fig. 1) will act as an additional element responsible for the stable seating of the helmet and protection against falling off the user's head.

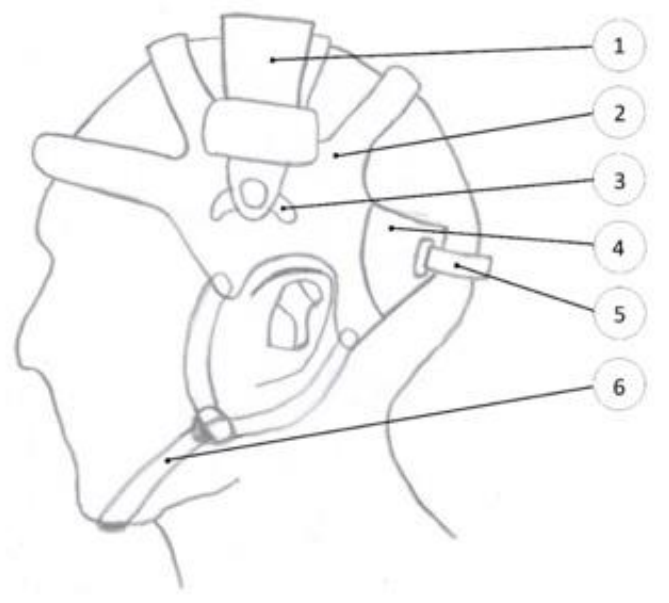

Fig. 1. Sketch of the concept [2]: 1 - shield, 2 - framework, 3 helmet hole, having the shape of a "bean", 4 - elastic elements, 5 - fastening belt, 6 - chinstrap

According to this concept, the authors developed a helmet design. To this end, they used CATIA v5 solid and surface modeling modules. The input element for the development of the helmet skeleton form was a mesh model - a scan of the head of an adult human (the authors had a model corresponding in size to a man measuring approximately 70th centile). Ultimately, the virtual model of the protective helmet was created (fig. 2), whose structure is hybrid (it is the result of surface and solid modeling).

The main skeleton is an approximate representation of the human head. However, so that the helmet does not constitute an unnecessary load, and at the same time provide the best ventilation of the surface of the head, three transverse notches were made in it. Additional circular ventilation holes have been made in the rest of the skeleton to promote perspiration evaporation and heat emission. 
In the inner part of the helmet there are also so-called sweat, i.e. absorbent lining that is in direct contact with the surface of the head. The skeleton has endings to attach the chin straps and the occipital part. Appropriate adjustment of the helmet to the size of the user's head is provided by appropriate cut-outs and narrowing in the thickness of the skeleton shell (made from the inside).

An important part of the helmet is the movable visor. It enables proper head protection in a place that must be protected. The helmet has a snap fastening system, easy to use and does not require the use of additional tools or help from a second person (especially a doctor). Thanks to a specially shaped hole in the lateral part of the skeleton, it is possible to move and fix the helmet in one of three angular positions (always so that the helmet covers one of the three notches). The opening edge and rounded tabs fixing the visor position are designed to be made of a softer and more elastic material (as opposed to the rest of the skeleton). In special cases, it is possible to place up to three guides in the mounting holes, which in practice means getting a full helmet. The helmet's task is not only to cover the outer surface of the head, but also to absorb dynamic loads from the outside (e.g. when falling or hitting the head with a hard object) and absorb the impact energy. This is facilitated by the material diversity between the skeleton and the edge of the helmet attachment hole (the attachment place is less rigid).

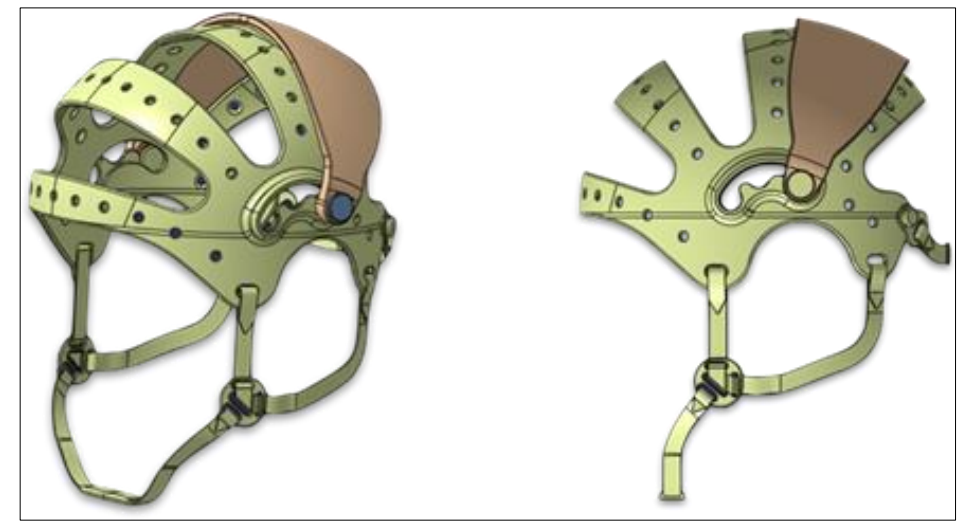

Fig. 2. Helmet's virtual model [2]

\section{Helmet analysis} $5)$.

The helmet model was used to perform simplified analyzes of ergonomics (fig. 3) and strength (figs. 4 and In the analysis of ergonomics, it was limited to adjusting the helmet model to the model of the human head and to check: possible collisions, characteristic places of the helmet (position of the headband of the skeleton, position of the holders for support straps, etc.) and the helmet's operation in the configuration with the largest number of visors installed.

However, the analysis of strength focused on verifying the helmet's resistance to static loads. For this purpose, boundary conditions were imposed on the helmet model in the form of a permanent fixation at the places of its natural attachment. The visor surface was loaded with a force of $700 \mathrm{~N}$ (estimated as a force corresponding to a falling impact of a $70 \mathrm{~kg}$ human impact with gravitational acceleration - with the theoretical assumption that at the time of contact of the helmet with the ground, the force will be distributed over the entire outer surface of the protective element).

As a material from which the helmet is ultimately to be made, polyether ether ketone (PEEK) was adopted. It is a thermoplastic, semi-crystalline plastic that combines good mechanical properties with resistance to high temperature and external chemical agents [8]. Thanks to this, this material is often successfully used in the medical industry (for the production of parts of surgical instruments), in dental prosthetics and in the construction of temporary implants for minimally invasive procedures. 


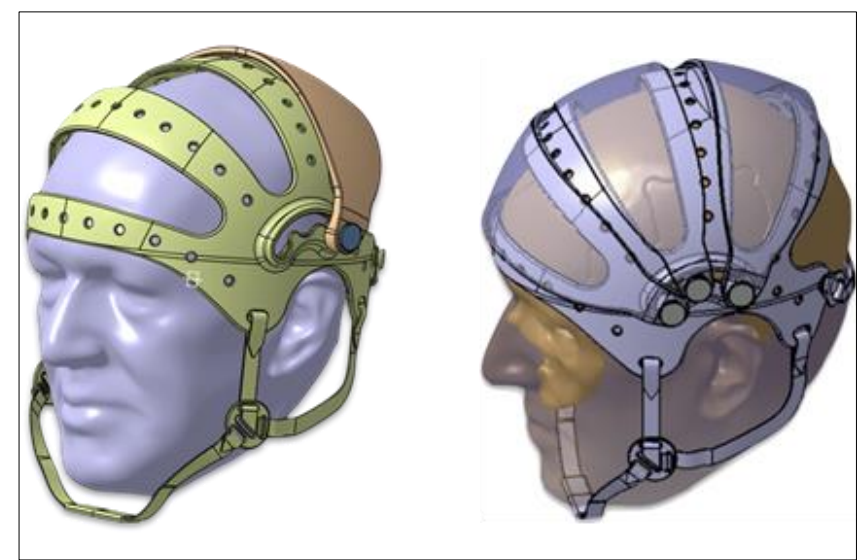

Fig. 3. View of the helmet model in various configurations together with the human head model [2]

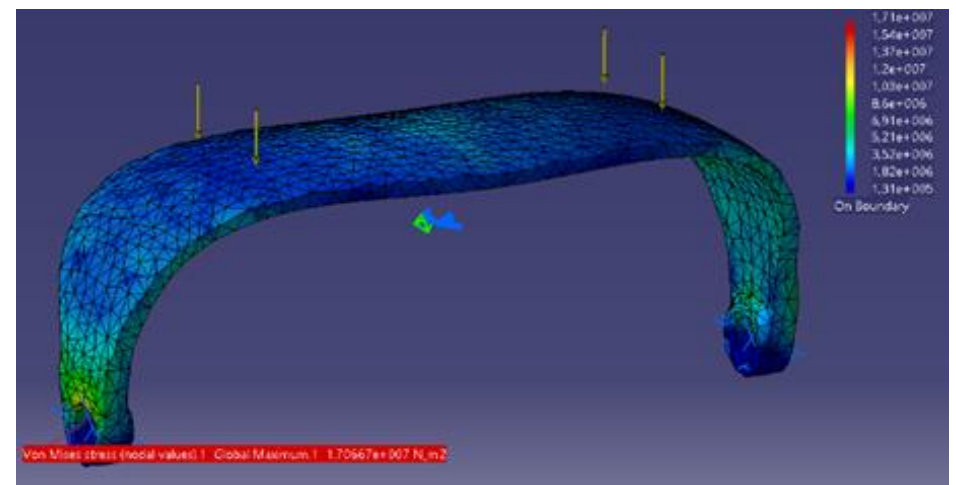

Fig. 4. Result of the finite element analysis - stress [2]

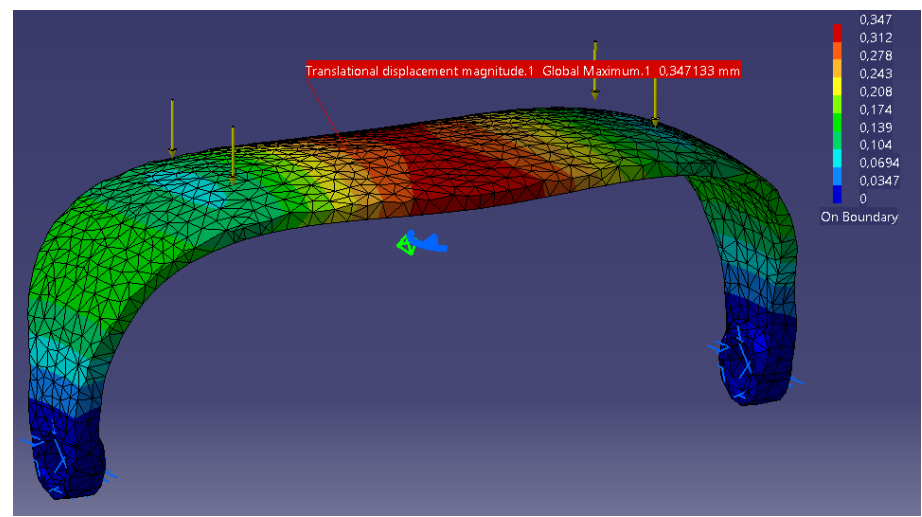

Fig. 5. Result of the finite element analysis - displacements [2]

The most important advantages of PEEK include:

- very good chemical resistance,

- high dimensional stability,

- biocompatibility (which allows contact with the skin for a long time),

- good sliding and friction properties,

- resistance to hydrolysis and superheated steam,

- high mechanical strength,

- susceptibility to sterilization with steam or ethylene oxide.

An additional advantage of PEEK as a visor material is that it can be used in the generative manufacturing process, especially for prototypes.

The tested visor was fully modeled as made of PEEK plastic with a yield strength of $114 \mathrm{MPa}$. The results of the analysis showed that the maximum stresses in the most loaded places, i.e. in the holes enabling the connection, were only $17 \mathrm{MPa}$, which is a small percentage of the yield strength of the material used. Even with a safety number of 5 , the allowable stress would not be exceeded ( $85 \mathrm{MPa}$ ). 
The maximum displacement achieved is $0.35 \mathrm{~mm}$, which is a real value in the case of a simulated fall.

To sum up, the results of the strength analysis of the visor model (figs. 4 and 5) are correct - neither large displacements nor exceeding of the strength limit were found.

\section{Summary}

This paper was intended to present the developed design of the adaptive protective helmet, as well as the made virtual model of this helmet.

Using the virtual helmet model, the necessary strength verification and ergonomic analysis were performed (the human head model was used in the ergonomic analysis).

According to the authors, the area of application of the developed helmet is not limited to the described rehabilitation in the case of cranioplasty. The helmet can also be successfully used in situations where it is necessary to protect any sensitive area of the head. The helmet can be used in the prevention of skull deformities and to protect the head in people with imbalances, as well as with the diagnosis of cerebral palsy, hemophilia, ataxia or spasticity.

\section{REFERENCES}

[1] Dujovny M., Aviles A., Agner C., Fernandez P., Charbel F.T. "Cranioplasty: Cosmetic or therapeutic". Surg Neurol. 47 (1997): 238-241.

[2] Frączek P. „Model wirtualny kasku ochronnego dla osób oczekujących na zabieg kranioplastyki”. Praca magisterska. Instytut Podstaw Konstrukcji Maszyn, Politechnika Śląska, 2017.

[3] Gedliczka A. „Atlas miar człowieka. Dane do projektowania i oceny ergonomicznej”. Warszawa: CIOP, 2001.

[4] Karbowski K., Urbanik A., Wyleżoł M. „Analiza obrazów i modelowanie wirtualne w konstruowaniu protez kości czaszki”. Mechanik. 7 (2010): 620-622.

[5] Kozubski W., Liberski P.P. „Neurologia”. Wydanie 1. Warszawa: Wydawnictwo Lekarskie PZWL, 2011.

[6] Tytyk E. „Projektowanie ergonomiczne”. Warszawa: Wydawnictwo Naukowe PWN, 2001.

[7] Wyleżoł M. „Metodyka modelowania na potrzeby inżynierii rekonstrukcyjnej”. Wydawnictwo Politechniki Śląskiej, 2013.

[8] Web site of Ensinger: https://www.ensingerplastics.com/pl-pl/polwyroby/tworzywawysokosprawne/peek (access: 20.08.2018 r.). 